\title{
Celiac plexus block increases quality of life in patients with pancreatic cancer
}

This article was published in the following Dove Medical Press journal: Journal of Pain Research

\author{
István Molnár' \\ Gabriella Hegyi ${ }^{1,2}$ \\ Lajos Zsom ${ }^{3}$ \\ Christine Saahs ${ }^{4,5}$ \\ Jan Vagedes ${ }^{6,7}$ \\ Gábor Kapócs ${ }^{8}$ \\ Zoltán Kovács' \\ Martin-Günther Sterner 9 \\ Henrik Szőke ${ }^{1,2}$ \\ 'Doctoral School of Health Sciences, \\ Faculty of Health Sciences, University \\ of Pécs, Pécs, Hungary; ${ }^{2}$ Department \\ of CAM, Faculty of Health Sciences, \\ University of Pécs, Pécs, Hungary; \\ ${ }^{3}$ Department of Nephrology, \\ Fresenius Medical Care, Cegléd, \\ Hungary; ${ }^{4}$ Department of Pediatrics, \\ University of Vienna, Vienna, Austria; \\ ${ }^{5}$ Pediatric Outpatient Department, \\ Krems, Austria; 'University Children's \\ Hospital, University of Tuebingen, \\ Tuebingen, Germany; ${ }^{7}$ Department \\ of Complementary and Integrative \\ Medicine, ARCIM Institute (Academic \\ Research in Complementary and \\ Integrative Medicine), Filderstadt, \\ Germany; ${ }^{8}$ Department of Psychiatry \\ and Psychiatric Rehabilitation, Saint \\ John Hospital, Budapest, Hungary; \\ ${ }^{9}$ Department of Medical Clinics I, \\ Klinikum Niederlausitz, Lauchhammer, \\ Germany
}

Correspondence: Henrik Szőke Department of CAM, Faculty of Health Sciences, University of Pécs, Vasvári Pál utca 4., 7622 Pécs, Hungary Email henrik.szoke@etk.pte.hu
Background: Pancreatic cancer is a malignant disease with a high mortality rate and severe pain that is challenging to manage. To reduce the excruciating abdominal pain, opioids and adjuvant agents are conventionally used.

Objectives: PRNCPB is a treatment of neural therapy. The number of studies assessing the effect on patients' QoL is limited and inconsistent. With this study, we intended to address this issue. Study design: A prospective nonrandomized study with a series of cases of unresectable pancreatic cancer was conducted.

Setting: The study was performed at our pain clinic under real life conditions.

Materials and methods: A total number of 16 patients with severe abdominal pain were enrolled in the study all of whom had responded to combined systemic analgesic therapy inadequately and had intolerable side effects contraindicating further increase in dose. The efficacy of this invasive, palliative analgesic procedure was evaluated 35 days after PRNCPB was performed. Primary outcomes were changed in pain intensity using the VAS questionnaire. Secondary outcomes were improved in QoL using the SF-36 questionnaire. Changes in pain medications and adverse reactions were monitored.

Results: After PRNCPB patients experienced a significant decrease $(P=0.002)$ in pain intensity as shown by the VAS score, and a decreased opiate demand. Their QoL scores considering effect sizes also improved $(P<0.001)$. No complications attributable to PRNCPB were observed during the study period. Additionally, no adverse drug reactions were observed.

Limitations: Detection, observation, and reporting bias can be estimated as moderate. Selection bias was not detected.

Conclusion: Our results give preliminary evidence that PRNCPB might be helpful as an additional treatment to conventional pain management in end-stage pancreatic cancer patients. PRNCPB seems to improve QoL in these patients in a time frame of at least 5 weeks after intervention.

Keywords: pancreatic cancer, cancer pain, celiac plexus, neural therapy, plexus block, palliative care, quality of life

\section{Introduction}

Pancreatic cancer is becoming more common worldwide; in Western countries, the disease ranks fourth to fifth in the list of cancers leading to death. It is more common in men than in women (male to female ratio 2:1), most prevalent in patients aged 55-75 years, in smokers, and those who regularly consume large amounts of alcohol. Other etiologic factors include aggregation in families, heredity, and obesity. ${ }^{1-3}$ Longterm survival is exceedingly low, such that the incidence of the disease is practically identical with its mortality. ${ }^{1,3-5}$ 
The first symptoms usually are weight loss, epigastric, or upper abdominal pain associated with icterus, pruritus, and anorexia. At the time of diagnosis, $73 \%$ of patients already suffer from abdominal pain. ${ }^{6,7}$ Few options are available to treat the severe pain typically present in advanced pancreatic cancer.

\section{Pathogenesis of tumor pain}

Pain in pancreatic cancer is typically located in the epigastrium radiating band-like to the back. Its etiology appears to be complex, possibly involving blockage in the pancreatic duct, increased parenchymal pressure, and superimposed peritumoral edema. At the level of nociception, the most important mechanism - estimated at $70 \%-90 \%$ - is the neuropathic pain associated with the infiltration of the nerves by cancer cells and perineural invasion. The neural processing of the pain includes four stages: transduction, transmission, modulation, and perception. ${ }^{8-10}$ The continuous impulse of permanent pain may result in the development of central pain syndrome. $^{9}$

\section{Management of tumor pain}

The pain caused by pancreatic cancer is of multifactorial origin, so the strategy of pain management should also be multifactorial. ${ }^{10-14}$ A well-chosen effective pain relief can significantly improve the QoL of patients including endstage cancer. ${ }^{15,16}$ The most widely accepted pain management strategy is the four-step "analgesic ladder" recommended by the WHO and IASP; ${ }^{17,18}$ it provides the most effective analgesia with relatively few side effects and complications. ${ }^{11,18,19}$ When conservative analgesia is no longer effective and the dose of analgesic can no longer be increased due to patient intolerance, invasive methods to control pain become more and more appropriate. ${ }^{19-21}$

Gastrointestinal, surgical, and oncological treatments and interventions aiming to maintain the patency of ducts and to reduce pancreas edema are necessary for adequate pain control. ${ }^{12,22,23}$ Despite these measures, severe pain often persists rendering the introduction of noninvasive and palliative methods unavoidable (Table 1). 17,18,24,25

In general, the preferred route of drug administration is enteral; however, transdermal application, rectal, subcutaneous, intramuscular, or intravenous drug administrations are also feasible. If the pain becomes intolerable after 5 days of therapy or if the intensity of pain reaches level 6 on the VAS before the fifth day, then the dose should be increased, the adjuvant drug should be replaced, or pain control should move a step higher. ${ }^{13,26,27}$

\section{Celiac plexus neurolysis}

The most effective method of invasive pain management in pancreatic cancer is $\mathrm{CPN}{ }^{28}$

In 1914, Kappis published his experience with the blockade of the splanchnic nerve and celiac plexus with a percutaneous technique. ${ }^{29}$ Despite various technical modifications, this study still remains the "gold standard." 30,31 The local anesthetic block of the plexus is effective in the early stage of cancer, but only for a short period. The efficacy rate of neurolysis is $\sim 80 \%$, reducing pain for several weeks or months. $^{32}$

CPN may be performed during laparotomy or thoracoscopy or by various percutaneous techniques: anterior or

Table I Treatment of cancer-related pain

\begin{tabular}{|l|l|l|l|l|}
\hline Pain intensity & I. Step & 2. Step & 3. Step & 4. Step \\
\hline & $\begin{array}{l}\text { I-3 } \\
\text { mild pain }\end{array}$ & $\begin{array}{l}4-6 \\
\text { moderate pain }\end{array}$ & $\begin{array}{l}\text { 7-10 } \\
\text { severe pain }\end{array}$ & $\begin{array}{l}7-10 \\
\text { severe pain }\end{array}$ \\
\hline Medications & $\begin{array}{l}\text { Nonopioid analgesics: } \\
\text { paracetamol, NSAID-s, } \\
\text { salicylate, selective COX-2 } \\
\text { inhibitors }\end{array}$ & $\begin{array}{l}\text { Drugs from first step + } \\
\text { mild opioids: codeine, } \\
\text { hydrocodeine, tramadol }\end{array}$ & $\begin{array}{l}\text { Drugs from second step + } \\
\text { strong opioids: morphine, } \\
\text { hydromorphone, fentanyl, } \\
\text { oxycodone, pethidine }\end{array}$ & $\begin{array}{l}\text { Drugs from third step + } \\
\text { neurolysis, nerve block, } \\
\text { spinal cord stimulations, } \\
\text { implanted opioid } \\
\text { pumps, radiofrequency } \\
\text { lesioning, cryotherapy }\end{array}$ \\
\cline { 2 - 6 } & $\begin{array}{l}\text { Adjuvant medications } \\
\text { (antidepressants, } \\
\text { anticonvulsants, } \\
\text { antispasmodics, } \\
\text { corticosteroids, local } \\
\text { anesthetics antiemetics) }\end{array}$ & $\begin{array}{l}\text { Adjuvant medications } \\
\text { (antidepressants, } \\
\text { anticonvulsants, } \\
\text { antispasmodics, } \\
\text { corticosteroids, local } \\
\text { anesthetics antiemetics) }\end{array}$ & $\begin{array}{l}\text { Adjuvant medications } \\
\text { (antidepressants, } \\
\text { anticonvulsants, } \\
\text { antispasmodics, } \\
\text { corticosteroids, local } \\
\text { anesthetics antiemetics) }\end{array}$ & $\begin{array}{l}\text { Adjuvant medications } \\
\text { antidepressants, } \\
\text { anticonvulsants, } \\
\text { antispasmodics, } \\
\text { corticosteroids, local } \\
\text { anesthetics antiemetics) }\end{array}$ \\
\hline
\end{tabular}


posterior paraspinal approach, intradiscal, retrocrural and transcrural, single and bilateral needle placements; transand para-aortic techniques; radiofrequency thermocoagulation; and using local anesthetics or neurolytics (6\%-10\% phenol, 70\%-90\% ethyl alcohol). ${ }^{33-36}$ Various imaging techniques can be used to perform these interventions accurately, including fluoroscopy, ultrasonography, or computed tomography. ${ }^{25,37-39}$

\section{Objectives}

The retrocrural technique of NCPB is known to minimize the incidence of complications. ${ }^{14,20,40}$ The number of publications using the retrocrural technique is limited. ${ }^{14,20,34,40-43}$ Thus, we aimed to evaluate the analgesic efficacy of retrocrural NCPB in patients with unresectable pancreatic cancer by monitoring changes in analgesic medication use, effective pain control, and therapy-related adverse reactions. Since the effect of NCPB on patient's QoL is considered controversial, ${ }^{44-50}$ with this study, we intended to address this issue.

\section{Study design}

This prospective nonrandomized study was performed at our pain clinic (Pándy Kálmán Hospital, Gyula, Hungary) under real life conditions following the principles of the Declaration of Helsinki. Patients with pancreatic cancer suffering from abdominal pain were included, if they fulfilled the study's inclusion criteria and provided signed informed consent. The approval by the local research ethics committee [Békés Megyei Központi Kórház Pándy Kálmán Tagkórháza, Intézeti Kutatásetikai Bizottság (IKEB)] was given under the registration number: $244 / 2016$. Patients were recruited in the period 06/01/2015-02/28/2017.

\section{Materials and methods Selection of patients}

Patients with pancreatic cancer who visited our pain clinic were enrolled in the study if they met the following inclusion criteria.

\section{Inclusion criteria}

- Diagnosis of unresectable pancreatic cancer;

- A high-dose, combination pain medication regimen had been used (opioids and NSAID) for the previous 2 weeks, or contraindication to increase dose was present due to adverse drug reactions;

- Pain intensity of 7 or more on VAS;

- Patient was capable of understanding the information provided and to give consent to the intervention.

\section{Exclusion criteria}

- Coagulation disorder or oral anticoagulant therapy.

- General contraindications to neural therapy.

\section{Evaluation - outcomes}

\section{Primary outcomes}

- Pain intensity was measured by a VAS before and 35 days after the intervention.

VAS is a simple method to assess pain intensity from 0 (no perceived pain) to 10 (maximum perceived pain). Although the value is subjective, comparison of the numeric data before and after treatment is a valid indicator of therapeutic efficacy. ${ }^{51-53}$

- Throughout the study type, application form and dosage of analgesic medication taken by the patients were monitored.

\section{Secondary outcomes}

QoL was assessed using the SF-36 questionnaire.

SF-36 is a generic, coherent, and easily administered qualityof-life questionnaire adapted in Hungary and recognized internationally. ${ }^{53,54}$ The questionnaire was completed individually before and 35 days after treatment. The administration time of the survey is $\sim 20$ minutes, and the patient can generally fill it out with little or no intervention from an interviewer.

"After" treatment results were compared with "before" treatment results. Patients' answers were presented in eight dimensions on a scale of $0-100$. The dimensions are vitality, physical functioning, bodily pain, general health perceptions, physical role functioning, emotional role functioning, social role functioning, and mental health. The higher the total value of the points of each dimension, the healthier the responder feels. ${ }^{55-57}$

\section{Side effects and complications}

Side effects and complications were monitored.

\section{Statistical evaluation}

An "internal control" of the post-treatment status compared with the pretreatment status was performed. The degree of changes was documented and analyzed. Change in pain intensity was calculated by Wilcoxon's test. The need for drug use was compared by using Fisher's exact test. Changes before and after treatments, in each dimension of the SF-36 questionnaire, were performed by Wilcoxon's test. A Bonferroni-Holmes method was used with $P$-values obtained 
in statistical tests mentioned above to decide which changes might be accepted as significant at $P<0.05$ taking into account the effect of multiple testing. Effect sizes were also calculated in cases of pain intensity and SF-36 dimensions. Data were recorded and analyzed using the SYSTAT 10 program package, as with previous studies and according to the SF-36 manual. ${ }^{55-57}$

\section{Description of the PRNCPB therapy Perioperative preparations}

Prior to the intervention, the condition of patients was assessed and optimized (eg, electrolyte and fluid balance, coagulation parameters) when necessary. The invasive intervention was performed in accordance with professional recommendations. Peripheral intravenous cannulation, $\mathrm{C}$-arm $\mathrm{X}$-ray with printer, and noniodinated contrast agent were used. Following the intervention, patients were observed in a surgical step down unit for 1 hour.

\section{Procedure}

Throughout the procedure, verbal communication was maintained with the patients. Heart rate, blood pressure, and $\mathrm{O}_{2}$ saturation were monitored. Patients were placed on the operating table in a prone position. In all cases, retrocrural penetration was performed: a horizontal line was drawn through the midline of the L1 vertebral body to the inferior edge of the 12 th rib, on both sides. A line was drawn to these from the processus spinosus of Th12, on both sides. The meeting point of the lines is the entry site which is located about $7.5 \mathrm{~cm}$ lateral to the midline, just beneath the 12 th ribs. Twenty-two gauge, $13-15 \mathrm{~cm}$ styleted needles are inserted bilaterally through the anesthetized areas. The needle is inserted medially at 45 degrees from the midline, so as to "walk off" the lateral surface of the L1 vertebral body. From here, the left-side needle is gradually advanced 2-4 cm deep, until the pulsations emanating from the aorta are felt. The right-side needle is inserted in $2-3 \mathrm{~cm}$ deeper past contact with the L1 vertebral body. From the needle to the right is the inferior vena cava. Finally, the tip of the two needles must be at the anterolateral edges of the aorta. About 2-2 mL of contrast material is injected bilaterally, and its spread observed radiographically. Ideally, on the fluoroscopic anteroposterior view, contrast material is confined to the midline and concentrated near the Th12-L1 vertebral body. A smooth posterior contour can be observed on the lateral view, in front of the vertebral body. If no aspirates were seen coming through the inserted needles and both needles were properly positioned, $5 \mathrm{~mL}$ of $1 \%$ lidocaine was injected per side. If this did not lead to deterioration or spinal block, the neurolysis was performed by using $20-20 \mathrm{~mL}$ of $70 \%$ ethyl alcohol. ${ }^{40,51}$ The intervention is depicted in Figure $1 .^{20}$

\section{Results}

We performed PRNCPB on a total of 16 pancreatic cancer patients. No exclusions occurred before and no dropouts occurred during the period of the study.

\section{Baseline characteristics}

Gender and age distribution of the patients were as follows: five men (rounded mean age: 57 years) and eleven women (rounded mean age: 66 years) were enrolled in the study. Comorbidities are depicted in Table 2.

\section{Primary outcomes}

- Five days prior to the onset of the study, subjects were at step 3 of the analgesic ladder. Each patient used a constant and high dose of major opioid and adjuvant analgesics. An increase in the dose of analgesics was not possible because of unbearable side effects. According to the WHO, the next analgesic step is the use of invasive pain therapy.

Pain intensity significantly decreased in the post-treatment period compared with pretreatment period based on VAS (Wilcoxon's test $P<0.001$; effect size: 0.632 and chisquared test: $P<0.001$; Figure 2).

- After NCPB, patients still had to continue taking oral analgesics, but their doses decreased compared with pretreatment dose. Although opioids could not be omitted in any of the cases, primarily because of metastatic pain, in each patient the need for previously taken pain medication decreased, either in strength (morphine could be dropped and replaced by dihydrocodeine) or dose, and no patient needed dose increase (Table 3).

\section{Secondary outcomes}

Results from the SF-36 survey revealed that pain reduction significantly improved (Wilcoxon's test, after Bonferroni-Holmes correction) at $P<0.05$ in five out of the eight dimensions (Table 4 and Figure 3 ). All but three dimensions increased significantly with median effect sizes.

\section{Side effects and complications}

The retrocrural PRNCPB has been reported to result in fewer side effects compared with NCPB performed by other 


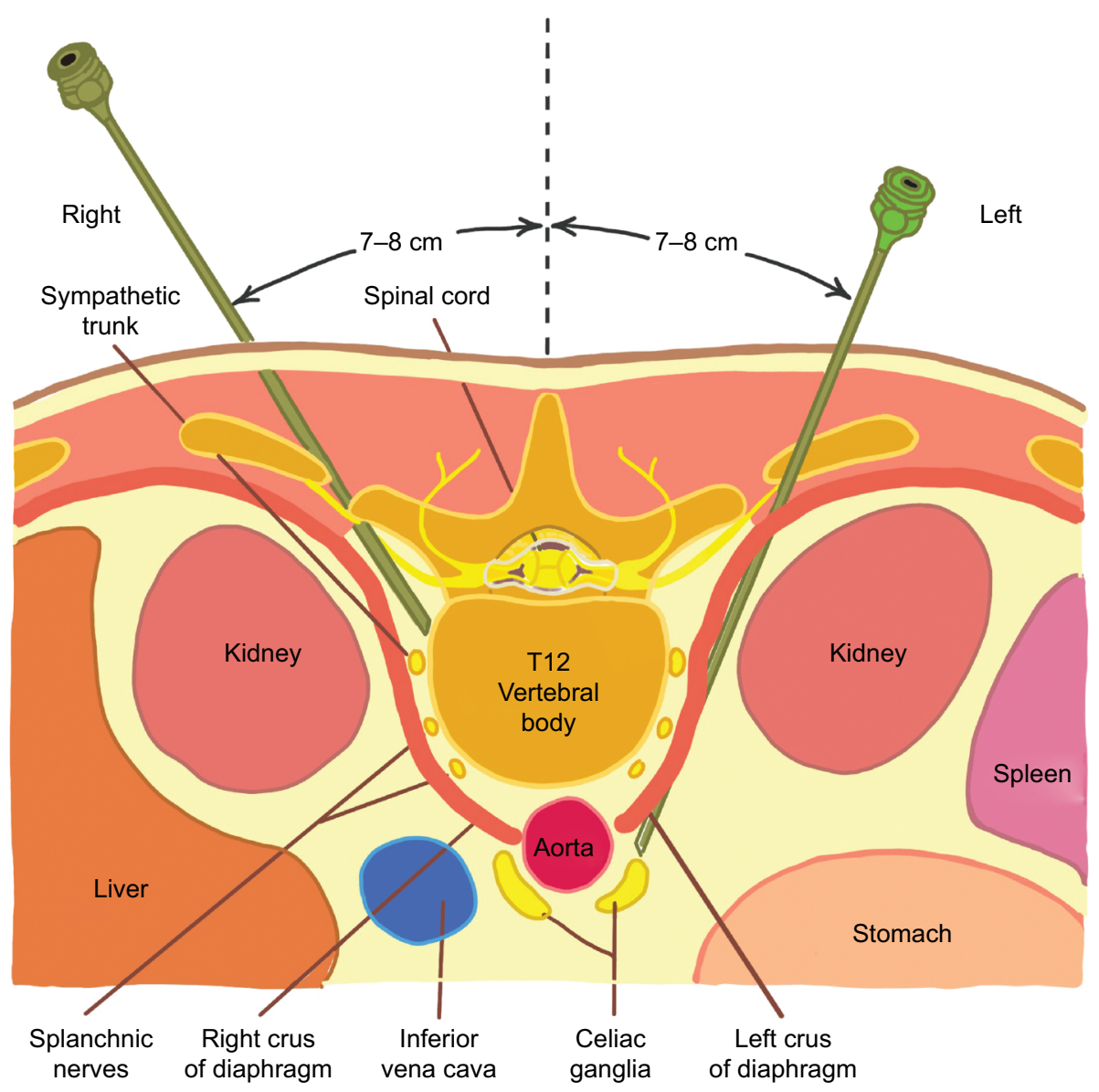

Figure I Anatomy of percutaneous retrocrural neurolytic celiac plexus block.

Table 2 Comorbidities of treated patients

\begin{tabular}{|c|c|c|c|c|c|c|c|c|c|c|}
\hline \multirow{2}{*}{$\begin{array}{l}\text { Gender/number } \\
\text { of patients }\end{array}$} & \multirow{2}{*}{$\begin{array}{l}\text { Age (years), } \\
\text { rounded } \\
\text { mean and } \\
\text { range }\end{array}$} & \multirow[t]{2}{*}{ SD } & \multicolumn{8}{|c|}{ Comorbidities } \\
\hline & & & CHD & PAD & HTN & $\begin{array}{l}\text { DM } \\
\text { (type I) }\end{array}$ & cHL & Obesity & Smoking & Depression \\
\hline Male/5 & $57(45-8 I)$ & 15.2 & 1 & 4 & 4 & 0 & 4 & I & 4 & I \\
\hline Female/II & $66(38-86)$ & 13.4 & 5 & 0 & 7 & I & 2 & 2 & 7 & 4 \\
\hline
\end{tabular}

Note: Obesity, BMI $=30-39.9 \mathrm{~kg} / \mathrm{m}^{2}$.

Abbreviations: CHD, coronary heart disease; $\mathrm{cHL}$, combined hyperlipidemia; DM, diabetes mellitus; HTN, hypertension; PAD, peripheral artery disease.

techniques. ${ }^{14,20,40}$ The most common undesirable effect is the pain caused by the intervention. ${ }^{43,54,58}$ During our study, the minimally invasive treatment resulted in only a short-term local irritation at the site of alcohol injection. Approximately 15-20 minutes following neurolysis, all patients had shortterm blood pressure drops, which all normalized within 5-10 minutes. This ratio did not exceed $10 \%$ of the baseline value and did not affect consciousness. Blood pressure was mainly normalized spontaneously or by the administration of intravenous fluid, in few cases by $5 \mathrm{mg}$ of ephedrini hydrochloridum. Diarrhea, ${ }^{40,60}$ postbleeding, neurological symptoms, acute abdominal symptoms, or other severe adverse effects or complications reported in the literature were not observed. ${ }^{8,25,29,31,44}$

\section{Discussion}

\section{Main findings}

1. Patients with severe pain were included in the study, whose doses of systemic combined analgesics were not increased due to the nontolerable side effects, but the intensity of the pain required more powerful analgesia.

2. A minimally invasive intervention was performed under real life outpatient conditions with low material, instrumental, and personal costs. 


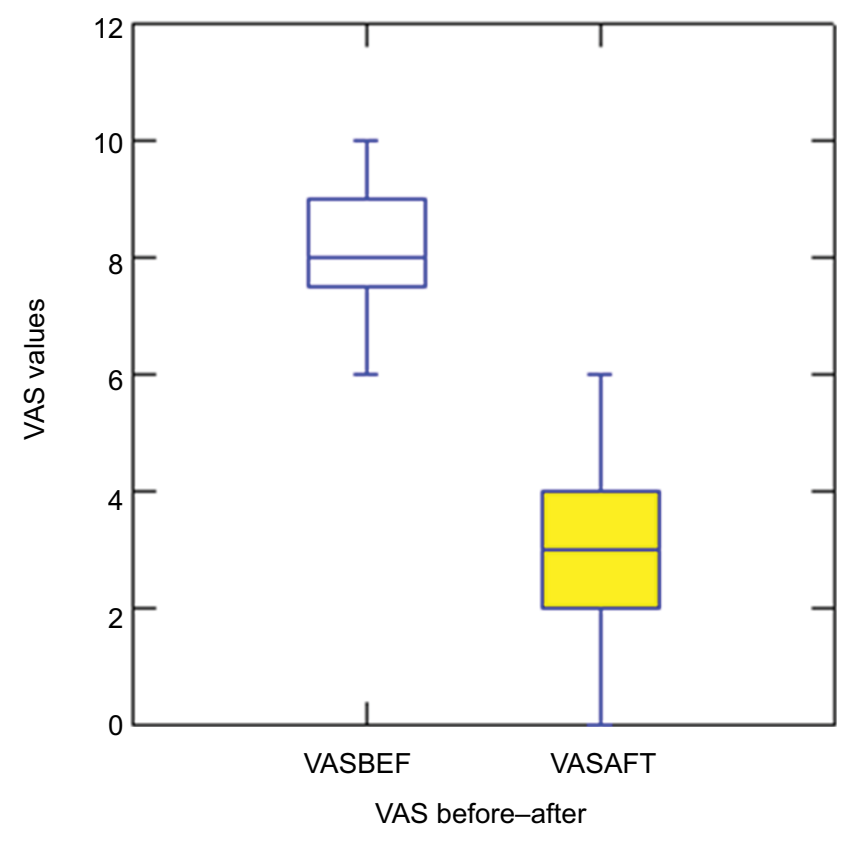

Figure 2 Pain intensity on VAS scale before and after treatment.
3. Validated methods were used to measure the effects of the therapy performed.

4. A significant effect could be achieved in pain reduction as well as in the improvement of the QoL.

5. Doses of analgesic medication (primarily morphine) could be reduced after the intervention.

6. Complications, side effects, and further hospitalization were not detected.

\section{Interpretation and comparison with previously published work}

Patients suffering from pancreatic cancer have a very short survival with intense pain influencing the quality of their everyday life. PRNCPB is an effective palliative therapy for the management of chronic, refractory, and celiac plexusmediated visceral pain. ${ }^{43,54,59}$ It is most often used when analgesic medications fail to control the pain. The number of studies assessing the effect of NCPB on patients' QoL

Table 3 Oral and transdermal analgesic medication of the patients with daily oral morphine equivalent dose (DOMED)

\begin{tabular}{|l|l|l|}
\hline Analgesic & $\begin{array}{l}\text { N (\%) patients } \\
\text { before PRNCPB }\end{array}$ & $\begin{array}{l}\text { N (\%) patients } \\
\text { after PRNCPB }\end{array}$ \\
\hline $2 \times 500 \mathrm{mg}$ acetylsalicylic acid tab. & $10(62.5)$ & $10(62.5)$ \\
\hline $3 \times 500 \mathrm{mg}$ acetaminophen (paracetamol) tab. & $6(37.5)$ & $6(37.5)$ \\
\hline $\begin{array}{l}2 \times 100 \mathrm{mg}(4 \times 50 \mathrm{mg}) \text { tramadol tab. } \\
(\text { DOMED }=20-80 \mathrm{mg} \text { morphine tab.) }\end{array}$ & 0 & $13(81.25)$ \\
\hline $\begin{array}{l}2 \times 60 \mathrm{mg} \text { oxycodone HCL tab. } \\
(\text { DOMED }=180-360 \mathrm{mg} \text { morphine tab.) }\end{array}$ & $4(25)$ & $3(18.75)$ \\
\hline $\begin{array}{l}\text { I00 } \mu \mathrm{g} / \mathrm{h} \text { fentanyl transdermal patch system } \\
\text { (DOMED }=720-1,000 \mathrm{mg} \text { morphine tab.) }\end{array}$ & $12(75)$ & 0 \\
\hline
\end{tabular}

Abbreviations: PRNCPB, percutaneous retrocrural neurolytic celiac plexus block; tab., tablet.

Table 4 SF-36 dimensions before and after treatment by all 16 patients

\begin{tabular}{|c|c|c|c|c|c|c|c|}
\hline $\begin{array}{l}\text { SF-36 } \\
\text { dimensions }\end{array}$ & $\begin{array}{l}\text { Effect } \\
\text { size }\end{array}$ & $\begin{array}{l}\text { Two-sided } \\
\text { probability }\end{array}$ & Median & Mean & SD & $\begin{array}{l}\text { 25th } \\
\text { percentile }\end{array}$ & $\begin{array}{l}\text { 75th } \\
\text { percentile }\end{array}$ \\
\hline FP-I & \multirow[t]{2}{*}{0.604} & \multirow[t]{2}{*}{$P=0.00 \mathrm{I}^{\mathrm{a}}$} & 22.500 & 27.187 & 21.132 & 13.75 & 36.25 \\
\hline FP-2 & & & 42.500 & 48.438 & 20.143 & 37.5 & 70.0 \\
\hline RP-I & \multirow[t]{2}{*}{0.364} & \multirow[t]{2}{*}{$P=0.039$} & 0.000 & 0.000 & 0.000 & 0 & 0 \\
\hline RP-2 & & & 0.000 & 12.500 & 22.361 & 0 & 25.0 \\
\hline BP-I & \multirow[t]{2}{*}{0.629} & \multirow[t]{2}{*}{$P<0.00 I^{a}$} & 0.000 & 5.125 & 8.065 & 0 & 12.0 \\
\hline BP-2 & & & 43.000 & 43.313 & 13.001 & 34.0 & 45.25 \\
\hline $\mathrm{GH}-\mathrm{I}$ & \multirow[t]{2}{*}{0.289} & \multirow[t]{2}{*}{$P=0.102$} & 10.000 & 9.688 & 9.031 & 3.75 & 11.25 \\
\hline $\mathrm{GH}-2$ & & & 10.000 & 10.750 & 10.847 & 3.75 & 12.5 \\
\hline VT-I & \multirow[t]{2}{*}{0.502} & \multirow[t]{2}{*}{$P=0.005^{\mathrm{a}}$} & 12.500 & 15.625 & 12.500 & 7.5 & 30.0 \\
\hline VT-2 & & & 30.000 & 28.125 & 19.847 & 10.0 & 41.25 \\
\hline SF-I & \multirow[t]{2}{*}{0.629} & \multirow[t]{2}{*}{$P<0.00 I^{a}$} & 0.000 & 7.000 & 11.136 & 0 & 15.25 \\
\hline SF-2 & & & 50.000 & 46.813 & 14.721 & 43.75 & 50.0 \\
\hline RE-I & \multirow[t]{2}{*}{0.306} & \multirow[t]{2}{*}{$P=0.083$} & 0.000 & 4.125 & 11.272 & 0 & 0 \\
\hline RE-2 & & & 0.000 & 10.313 & $|5.62|$ & 0 & 33.0 \\
\hline $\mathrm{MH}-\mathrm{I}$ & \multirow[t]{2}{*}{0.544} & \multirow[t]{2}{*}{$P=0.002^{\mathrm{a}}$} & 18.000 & 21.750 & 13.061 & 12.0 & 32.0 \\
\hline $\mathrm{MH}-2$ & & & 32.000 & 33.000 & $16.62 \mid$ & 23.0 & 44.0 \\
\hline
\end{tabular}

Note: I - Before therapy; 2 - After therapy. aSignificant difference.

Abbreviations: BP, bodily pain; FP, physical functioning, physical health problems; GH, general health perceptions; $\mathrm{MH}$, mental health, emotional well-being; RE, emotional role functioning, emotional health problems; RP, physical role functioning; SF, social role functioning; SF-36, Short Form-36; VT, vitality, energy/fatigue. 


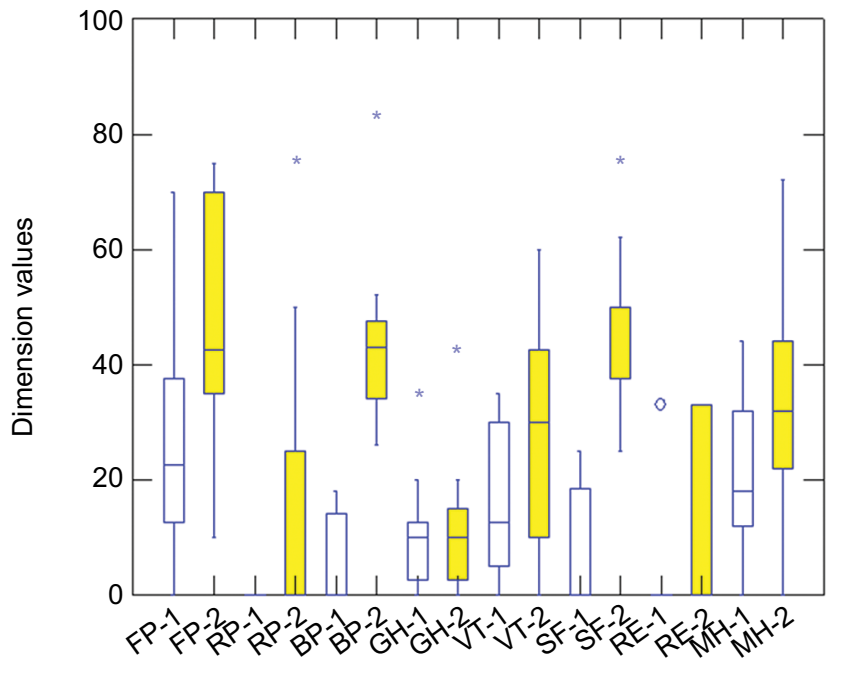

SF-36 dimensions (before=1; after=2)

Figure 3 SF-36 dimensions before and after treatment.

Abbreviations: $\mathrm{GH}$, general health perceptions; $\mathrm{MH}$, mental health, emotional well-being; FP, physical functioning, physical health problems; RE, emotional role functioning, emotional health problems; RP, physical role functioning; SF, social role functioning; VT, vitality, energy/fatigue.

is limited, and there is inconsistency in the effect of NCPB on QoL. ${ }^{14,44-50,60,64,65}$ This study gives preliminary evidence that NCBP might be effective both in controlling pain and in improving QoL which means that $\mathrm{NCPB}$ could provide important benefits for patients suffering from pain associated with advanced pancreatic cancer.

\section{Limitations}

\section{Regarding patients}

The small number of subjects in our study makes it difficult to draw definitive conclusions. Further, no control group has been included into our study, eg, receiving standard care (waiting control group) or other complementary treatments.

\section{Regarding methods}

Due to legal, ethical, and professional reasons, we could not have a blinded control group.

A further limitation is the relatively short follow-up period of 35 days in comparison with a 3- or 6-month followup assessment, which has been realized in other studies. ${ }^{44,48}$ Most patients reach step 4 of cancer-related pain treatment (see Table 1) in the last stage of their illness. This was the background to determine a limited period of data collection in the study design. Nevertheless, in the run-on survey, it could be assessed that during the next 35-42 days period after closing the data collection (ie, the first 35 days after the intervention) no deterioration of symptoms or pain medication was detected.

No concurrent and additional treatments that might have been applied during the follow-up period have been monitored.

To assess the effect of pain relief on patient's QoL, we used the standardized VAS and SF-36 derived from the General Health Survey of the Medical Outcomes Study by Stewart et al. ${ }^{61}$ While VAS may be less commonly used than other standard methods in this setting [such as the Care Preferences with Pain, Enjoyment, General Activity Scale (PEG) or the Brief Pain Inventory], out of practical reasons we decided to use VAS. Although SF-36 Health Survey is usually not a first-line standard scale for seriously ill patients, we did not identify any problems or bias.

\section{Bias}

Outset bias regarding baseline characteristics of the patients can be described as follows. Age distribution of patients peaks between 55 and 75 years for pancreatic cancer. Although pancreatic cancer is generally more common in men than in women $(2: 1)$, the fact that in our study this proportion appeared to be reversed was not likely to result any bias.

Detection, observation, and reporting bias can be estimated as moderate. Differences in distribution and medication of comorbidities should not have affected the outcomes. Selection bias was not detected, as no exclusions occurred before and no dropouts occurred during the period of the investigation.

In our study, we did not evaluate the effect of palliative pain management on survival rate, thus it has been previously demonstrated that effective pain relief does not result in increased survival. ${ }^{44,62}$

The three dimensions of SF-36, which did not change significantly, were general perception of health and emotional role functioning. As patients are aware of their incurable, endstage status, it is very likely that it influences their general health perception and emotions.

\section{Generalizability of the treatment - aspects for safety and training}

The clinical and practical experience of complications has been rare. ${ }^{8,14,20,25,29,31,40,43,44,54,58,63,66}$ Through official training courses - as established at the University of Pécs - risks are minimized. With sufficient anatomical knowledge, the PRNCPB is easy to acquire. Average neural therapeutic 
devices are needed for the intervention in inpatient or outpatient clinical setting.

\section{Conclusion}

The results of this study underline the preliminary evidence and our overall clinical experience over 20 years that PRNCPB might help end-stage pancreatic cancer patients in reducing pain and in improving QoL even if only for a short period of time. ${ }^{67-70}$

\section{Abbreviations}

CPN, celiac plexus neurolysis; IASP, International Association for Study of Pain; NCPB, neurolytic celiac plexus block; PRNCPB, percutaneous retrocrural neurolytic celiac plexus block; QoL, quality of life; SF-36, Short Form-36.

\section{Acknowledgment}

We dedicate this paper to the University of Pécs in commemoration of the 650th anniversary of its foundation.

\section{Disclosure}

The authors report no conflicts of interest in this work.

\section{References}

1. American Cancer Society. Cancer epidemiology. Biomarkers Prev. 2005;14:1-9.

2. Siegel RL, Miller KD, Jemal A. Cancer statistics, 2018. CA Cancer J Clin. 2018;68(1):7-30.

3. Hagen NA. Epidemiology, prevalence, and cancer pain syndromes. In: Fishman SM, Ballantyne J, Rathmell J, editors. Bonica's Management of Pain. Baltimore, Philadelphia: Lippincott, Williams \& Wilkins; 2010;537-558.

4. Ilic M, Ilic I. Epidemiology of pancreatic cancer. World J Gastroenterol. 2016;22(44):9694-9705.

5. Olson SH, Kurtz RC. Epidemiology of pancreatic cancer and the role of family history. J Surg Oncol. 2013;107(1):1-7.

6. Caraceni A, Portenoy RK. An international survey of cancer pain characteristics and syndromes. IASP Task Force on Cancer Pain. International Association for the Study of Pain. Pain. 1999;82(3):263-274.

7. Portenoy RK. Treatment of cancer pain. Lancet. 2011;377(9784): 2236-2247.

8. Fitzgibbon DR. Mechanisms, assessment, and diagnosis of pain due to cancer. In: Fishman SM, Ballantyne JC, Rathmell JP, editors. Bonica's Management of Pain 4th Edition. Baltimore, Philadelphia: Lippincott Williams \& Wilkins; 2010:559-582.

9. Barreto SG, Saccone GT. Pancreatic nociception - revisiting the physiology and pathophysiology. Pancreatology. 2012;12(2):104-112.

10. Lebovits AH, Lefkowitz M. Pain management of pancreatic carcinoma: a review. Pain. 1989;36(1):1-11.

11. Brennan F, Carr DB, Cousins M. Pain management: a fundamental human right. Anesth Analg. 2007;105(1):205-221.

12. Mosca F, Giulianotti PC, Balestracci T, et al. Long-term survival in pancreatic cancer: pylorus-preserving versus Whipple pancreatoduodenectomy. Surgery. 1997;122(3):553-566.

13. Passik SD, Kirsh KL, Casper D. Addiction-related assessment tools and pain management: Instruments for screening, treatment planning, and monitoring compliance. Pain Medicine. 2008;9(2):S145-S166.
14. Tewari S, Agarwal A, Dhiraaj S, et al. Comparative evaluation of retrocrural versus transaortic neurolytic celiac plexus block for pain relief in patients with upper abdominal malignancy: a retrospective observational study. Indian J Palliat Care. 2016;22(3):301-306.

15. Kristensen A, Vagnildhaug OM, Grønberg BH, Kaasa S, Laird B, Solheim TS. Does chemotherapy improve health-related quality of life in advanced pancreatic cancer? A systematic review. Crit Rev Oncol Hematol. 2016;99:286-298.

16. Heerkens HD, Tseng DS, Lips IM, et al. Health-related quality of life after pancreatic resection for malignancy. Br J Surg. 2016;103(3):257-266.

17. Dobosz L, Stefaniak T, Dobrzycka M, et al. Invasive treatment of pain associated with pancreatic cancer on different levels of WHO analgesic ladder. BMC Surg. 2016;16:20.

18. Childers JW, King LA, Arnold RM. Chronic pain and risk factors for opioid misuse in a palliative care clinic. Am J Hosp Palliat Care. 2015;32(6):654-659.

19. Hui D, Bruera E. A personalized approach to assessing and managing pain in patients with cancer. J Clin Oncol. 2014;32(16):1640-1646.

20. Waldman S. Atlas of Interventional Pain Management. 4th edn. Philadelphia, PA, USA: Elsevier Health Sciences; 2014;374-381.

21. Karapanos K, Nomikos IN. Current surgical aspects of palliative treatment for unresectable pancreatic cancer. Cancers (Basel). 2011;3(1):636-651.

22. Alexakis N, Halloran C, Raraty M, Ghaneh P, Sutton R, Neoptolemos JP. Current standards of surgery for pancreatic cancer. Br J Surg. 2004;91(11):1410-1427.

23. Masuda T, Kuramoto M, Shimada S, et al. Splanchnicectomy for pancreatic cancer pain. Biomed Res Int. 2014;2014:941726.

24. Andersen JR, Sørensen SM, Kruse A, Rokkjaer M, Matzen P. Randomised trial of endoscopic endoprosthesis versus operative bypass in malignant obstructive jaundice. Gut. 1989;30(8):1132-1135.

25. Iki K, Fujita Y, Inada H, Satoh M, Tsunoda T. Celiac plexus block: evaluation of injectate spread by three-dimensional computed tomography. Abdom Imaging. 2003;28(4):571-573.

26. Breivik H, Borchgrevink PC, Allen SM, et al. Assessment of pain. $\mathrm{Br}$ J Anaesth. 2008;101(1):17-24.

27. World Health Organization, editor. Cancer Pain Relief, with a Guide to Opioid Availability. 2nd edn. Geneva: WHO; 1996;1-70.

28. Arcidiacono PG, Rossi M. Celiac plexus neurolysis. JOP. 2004;5(4): 315-321.

29. Kappis M. Erfahrungen mit Lokalanästhesie bei Bauchoperationen [Experience with local anesthesia in abdominal surgery]. Verh Dtsch Gesellsch Chir. 1914;43:87-89. German.

30. Underwood RA, Wu JS, Quasebarth MA, Brunt LM. Development of a laparoscopic approach to neurolytic celiac plexus block in a porcine model. Surg Endosc. 2000;14(9):839-843.

31. Wang PJ, Shang MY, Qian Z, Shao CW, Wang JH, Zhao XH. CT-guided percutaneous neurolytic celiac plexus block technique. Abdom Imaging. 2006;31(6):710-718.

32. Gao L, Yang YJ, Xu HY, et al. A randomized clinical trial of nerve block to manage end-stage pancreatic cancerous pain. Tumour Biol. 2014;35(3):2297-2301.

33. Ischia S, Luzzani A, Ischia A, Faggion S. A new approach to the neurolytic block of the coeliac plexus: the transaortic technique. Pain. 1983;16(4):333-341.

34. Ischia S, Ischia A, Polati E, Finco G. Three posterior percutaneous celiac plexus block techniques. A prospective, randomized study in 61 patients with pancreatic cancer pain. Anesthesiology. 1992;76(4):534-540.

35. Muehle C, Vansonnenberg E, Casola G, Wittich G, Polansky A. Radiographically guided alcohol block of the celiac ganglia. Semin Intervent Radiol. 1987;4(03):195-199.

36. De Cicco M, Matovic M, Balestreri L, Fracasso A, Morassut S, Testa V. Single-needle celiac plexus block: is needle tip position critical in patients with no regional anatomic distortions? Anesthesiology. 1997;87(6):1301-1308.

37. Sakamoto H, Kitano M, Komaki T, Imai H, Kamata K, Kudo M. Endoscopic ultrasound-guided neurolysis in pancreatic cancer. Pancreatology. 2011;11(Suppl 2):52-58. 
38. Puli SR, Reddy JB, Bechtold ML, Antillon MR, Brugge WR. EUSguided celiac plexus neurolysis for pain due to chronic pancreatitis or pancreatic cancer pain: a meta-analysis and systematic review. Dig Dis Sci. 2009;54(11):2330-2337.

39. Wyse JM, Chen YI, Sahai AV. Celiac plexus neurolysis in the management of unresectable pancreatic cancer: when and how? World $J$ Gastroenterol. 2014;20(9):2186-2192.

40. Weber JG, Brown DL, Stephens DH, Wong GY. Celiac plexus block. Retrocrural computed tomographic anatomy in patients with and without pancreatic cancer. Reg Anesth. 1996;21(5):407-413.

41. Erdek MA, Halpert DE, González Fernández M, Cohen SP. Assessment of celiac plexus block and neurolysis outcomes and technique in the management of refractory visceral cancer pain. Pain Med. 2010;11(1):92-100.

42. Ugur F, Gulcu N, Boyaci A. Celiac plexus block with the long stylet needle technique. Adv Ther. 2007;24(2):296-301.

43. Rykowski JJ, Hilgier M. Efficacy of neurolytic celiac plexus block in varying locations of pancreatic cancer: influence on pain relief. Anesthesiology. 2000;92(2):347-354.

44. Wong GY, Schroeder DR, Carns PE, et al. Effect of neurolytic celiac plexus block on pain relief, quality of life, and survival in patients with unresectable pancreatic cancer: a randomized controlled trial. JAMA. 2004;291(9):1092-1099.

45. Yan BM, Myers RP. Neurolytic celiac plexus block for pain control in unresectable pancreatic cancer. Am J Gastroenterol. 2007;102(2):430-438.

46. Mercadante S, Catala E, Arcuri E, Casuccio A. Celiac plexus block for pancreatic cancer pain: factors influencing pain, symptoms and quality of life. J Pain Symptom Manage. 2003;26(6):1140-1147.

47. Jain PN, Shrikhande SV, Myatra SN, Sareen R. Neurolytic celiac plexus block: a better alternative to opioid treatment in upper abdominal malignancies: an Indian experience. J Pain Palliat Care Pharmacother. 2005;19(3):15-20.

48. Kawamata $\mathrm{M}$, Ishitani $\mathrm{K}$, Ishikawa $\mathrm{K}$, et al. Comparison between celiac plexus block and morphine treatment on quality of life in patients with pancreatic cancer pain. Pain. 1996;64(3):597-602.

49. Nagels W, Pease N, Bekkering G, Cools F, Dobbels P. Celiac plexus neurolysis for abdominal cancer pain: a systematic review. Pain Med. 2013;14(8):1140-1163.

50. Zhang CL, Zhang TJ, Guo YN, et al. Effect of neurolytic celiac plexus block guided by computerized tomography on pancreatic cancer pain. Dig Dis Sci. 2008;53(3):856-860.

51. McCormack HM, Horne DJ, Sheather S. Clinical applications of visual analogue scales: a critical review. Psychol Med. 1988;18(4):1007-1019.

52. Johnson C. Measuring Pain. Visual analog scale versus numeric pain scale: what is the difference? J Chiropr Med. 2005;4(1):43-44.

53. Czimbalmos Á, Nagy Z, Varga Z, Husztik P. Páciens megelégedettségi vizsgálat SF-36 kérdőívvel, a magyarországi normálértékek meghatározása [Patient Satisfaction Survey with SF-36 questionnaire, definition of normal values in Hungary]. Népegészségügy. 1999;1:4-19. Hungarian.

54. Dobosz $Ł$, Kaczor M, Stefaniak TJ. Pain in pancreatic cancer: review of medical and surgical remedies. ANZ J Surg. 2016;86(10):756-761.
55. McHorney CA, Ware JE Jr, Lu JF, Sherbourne CD. The MOS 36-item Short-Form Health Survey (SF-36): III. Tests of data quality, scaling assumptions, and reliability across diverse patient groups. Med Care. 1994;32(1):40-66.

56. Ware JE Jr, Sherbourne CD. The MOS 36-item short-form health survey (SF-36). I. Conceptual framework and item selection. Med Care. 1992;30(6):473-483.

57. Ware JE, Snow KK, Kosinski M, Gandek B. SF-36 health survey. In: Manual and Interpretation Guide. New England Medical Center Hospital. Boston, MA: The Health Institute; 1993;3(1-9):32.

58. Polati E, Finco G, Gottin L, Bassi C, Pederzoli P, Ischia S. Prospective randomized double-blind trial of neurolytic coeliac plexus block in patients with pancreatic cancer. Br J Surg. 1998;85(2):199-201.

59. Cao J, He Y, Liu H, et al. Effectiveness of percutaneous celiac plexus ablation in the treatment of severe cancer pain in upper abdomen and evaluation of health economics. Am J Hosp Palliat Care. 2017;34(2):142-147.

60. Shwita AH, AmrYM, Okab MI. Comparative study of the effects of the retrocrural celiac plexus block versus splanchnic nerve block, c-arm guided, for upper gastrointestinal tract tumors on pain relief and the quality of life at a six-month follow up. Korean J Pain. 2015;28(1):22-31.

61. Stewart AL, Hays RD, Ware JE Jr. The MOS short-form general health survey. Reliability and validity in a patient population. Med Care. 1988;26(7):724-735.

62. Oh TK, Lee WJ, Woo SM, Kim NW, Yim J, Kim DH. Impact of celiac plexus neurolysis on survival in patients with unresectable pancreatic cancer: a retrospective, propensity score matching analysis. Pain Physician. 2017;20(3):E357-E365.

63. Molnár I, Szőke H, Hegyi G. Effects of neural therapy on quality of life in patients suffering from Raynaud syndrome. Eur J Integr Med. 2018;18:59-65.

64. Cao J, He Y, Liu H, et al. Effectiveness of percutaneous celiac plexus ablation in the treatment of severe cancer pain in upper abdomen and evaluation of health economics. Am J Hosp Palliat Care 2017;34(2):142-147.

65. Süleyman Ozyalçin N, Talu GK, Camlica H, Erdine S. Efficacy of coeliac plexus and splanchnic nerve blockades in body and tail located pancreatic cancer pain. Eur J Pain. 2004;8(6):539-545.

66. Yang A, Brown J, Mak E. Persistent diarrhea after celiac plexus block in a pancreatic cancer patient: case report and literature review. $J$ Palliat Med. 2016;19(1):83-86.

67. Warner NS, Trousdale ER, Lamer TJ. Novel single-needle approach for retrocrural celiac plexus blockade using fluoroscopic guidance. $A$ A Pract. Epub 2018 Oct 1 .

68. Sachdev AH, Gress FG. Celiac plexus block and neurolysis: a review. Gastrointest Endosc Clin N Am. 2018 Oct;28(4):579-586.

69. Wyse JM, Sahai AV. Endoscopic ultrasound-guided management of pain in chronic pancreatitis and pancreatic cancer: an update. Curr Treat Options Gastroenterol. Epub 2018 Sep 12.

70. Drewes AM, Campbell CM, Ceyhan GO, et al. Pain in pancreatic ductal adenocarcinoma: a multidisciplinary, International guideline for optimized management. Pancreatology. 2018;18(4):446-457.
Journal of Pain Research

\section{Publish your work in this journal}

The Journal of Pain Research is an international, peer reviewed, open access, online journal that welcomes laboratory and clinical findings in the fields of pain research and the prevention and management of pain. Original research, reviews, symposium reports, hypothesis formation and commentaries are all considered for publication.
The manuscript management system is completely online and includes a very quick and fair peer-review system, which is all easy to use. Visit http://www.dovepress.com/testimonials.php to read real quotes from published authors. 